\title{
Open Letter: Scientists stand up to protect academic whistleblowers and post-publication peer review.
}

\author{
Lonni Besançon, ${ }^{1}$ Alexander Samuel, ${ }^{2}$ Thibault G. Sana, ${ }^{3}$ Mathieu E. Rebeaud, ${ }^{4}$ Anthony \\ Guihur, ${ }^{4}$ Marc Robinson-Rechavi, ${ }^{5}$ Nicolas Le Berre, ${ }^{6}$ Matthieu Mulot, ${ }^{7}$ Gideon Meyerowitz- \\ Katz, ${ }^{8}$ Hervé Maisonneuve, ${ }^{9}$ Brian A. Nosek. ${ }^{10,11}$ \\ 1Faculty of Information and Technology, Monash University, Australia. lonni.besancon@gmail.com
${ }^{2}$ Association de Toxicologie Chimie de Paris, France. alexander.samuel@laposte.net
${ }^{3}$ LIPME, Université de Toulouse, INRAE, CNRS, 31320 Castanet-Tolosan, France. thibault.sana@inrae.fr
${ }^{4}$ Department of Plant Molecular Biology, Faculty of Biology and Medicine, University of Lausanne, Switzerland.
anthony.guihur@gmail.com rebeaud.mat@gmail.com
}

${ }^{5}$ Department of Ecology and Evolution, Faculty of Biology and Medicine, University of Lausanne, Switzerland. marc.robinsonrechavi@unil.ch

${ }^{6}$ Intensive Care Unit, Metz-Thionville Regional Hospital, France. n.leberre84@gmail.com

${ }^{7}$ Laboratory of Soil Biodiversity, University of Neuchâtel, 2000 Neuchâtel Switzerland. matthieu.mulot@unine.ch

${ }^{8}$ School of health and society, University of Wollongong, Australia. gidmk.healthnerd@gmail.com

${ }^{9}$ Research Integrity Officer, Schools of Medicine, University of Paris, \& Consultant, Paris France. hervemaisonneuve@gmail.com

${ }^{10}$ Professor, Department of Psychology, University of Virginia, Charlottesville, Virginia USA.

${ }^{11}$ Executive Director, Center for Open Science, Charlottesville, Virginia USA. nosek@virginia.edu

For years, Dr. Elisabeth Bik has contributed immensely to scientific research through her much needed and difficult work on detecting errors in published scientific communications. She has detected and reported over 4000 image duplications and manipulations, data concerns, plagiarism cases, and human and animal ethics breaches through comments on the postpublication review platform PubPeer, social media, and her website Science Integrity Digest. She has also contacted hundreds of editorial boards of journals to report on errors or potential scientific fraud. Nature credited Dr. Bik as the "public face of image sleuthing" [1] and her work has been awarded the 2021 Peter Wildy Prize Lecture from the UK Microbiology Society.

Dr. Bik's work is instrumental to ethical, sound, and reproducible research, but it also introduces her to personal risk as a whistleblower. In one case, she identified image duplication and potential ethical issues in 62 published articles from Prof. Didier Raoult and his institute some of which have also been echoed in published scientific communication $[2,3,4]$. For several months, Prof. Raoult and some other members of his institute have responded by insulting her on national television, disclosing her personal address on social media, and threatening legal action for harassment and defamation. Prof. Raoult and his team's behaviour toward Dr. Bik and others have been pointed out by many international media outlets such as Times Higher Education or Scientific American. This strategy of harassment and threats creates a chilling effect for whistleblowers and for scholarly criticism more generally $[5,6,7]$. Scholarly criticism, particularly on issues of research integrity, is fraught with challenges. This makes it particularly important to maintain focus on addressing such critique with scientific evidence and not attacks on people's appearance, character, or person. 
The authors and the co-signatories of this open letter are scientists dedicated to transparency and integrity of research. We support the work needed to investigate potential errors and possible misconduct and believe the scientific community can do more to protect whistleblowers against harassment and threats. Individual researchers can provide vocal support for whistleblowers and against harassment to shift norms. Journals, funders, policymakers, and institutions can make explicit policies that protect whistleblowers and establish fair, judicious, and transparent processes for addressing potential misconduct that protect all participants. With this letter, we show our support for post-publication peer-review, to Elisabeth Bik and her work, and to all the whistleblowers that help maintain quality, honesty, integrity and trustworthiness of scientific advances.

\section{References:}

[1] Shen, H. (2020). Meet this super-spotter of duplicated images in science papers. Nature, 581(7807), 132-136. doi: https://doi.org/10.1038/d41586-020-01363-z

[2] Marcus, A. A. (2020, May 22). Hydroxychloroquine-COVID-19 study did not meet publishing society's "expected standard." Retraction Watch. https://retractionwatch.com/2020/04/06/hydroxychlorine-covid-19-studydid-not-meet-publishing-societys-expected-standard/

[3] Rosendaal FR. Review of: "Hydroxychloroquine and azithromycin as a treatment of COVID-19: results of an open-label non-randomized clinical trial" Gautret et al. 2020. https://doi.org/10.1016/j.ijantimicag.2020.105949. Int J Antimicrob Agents. 2020, https://doi.org/10.1016/i.ijantimicag.2020.106063

[4] Lonni Besançon, Nathan Peiffer-Smadja, Corentin Segalas, Haiting Jiang, Paola Masuzzo, Cooper Smout, Eric Billy, Maxime Deforet, Clémence a. Open Science Saves Lives: Lessons from the COVID-19 PandemicbioRxiv 2020.08.13.249847; doi: https://doi.org/10.1101/2020.08.13.249847

[5] Samer, C., Lacombe, K., \& Calmy, A. (2021). Cyber harassment of female scientists will not be the new norm. The Lancet Infectious Diseases, 21(4), 457-458. Doi: https://doi.org/10.1016/s1473-3099(20)30944-0

[6] Peiffer-Smadja, N., Rebeaud, M. E., Guihur, A., Mahamat-Saleh, Y., \& Fiolet, T. (2020). Hydroxychloroquine and COVID-19: a tale of populism and obscurantism. The Lancet Infectious Diseases. Doi: https://doi.org/10.1016/S1473-3099(20)30866-5

[7] Ektorp, E. (2020). Death threats after a trial on chloroquine for COVID-19. The Lancet. Infectious Diseases, 20(6), 661. Doi: https://doi.org/10.1016/S1473-3099(20)30383-2 